\title{
Tek Duvarlı Karbon Nanotüp Takviyesinin Levha Kalıplama Bileşiğinin Mekanik ve İletkenlik Özelliklerine Etkisinin İncelenmesi
}

\author{
Investigation of the Effect of Single-Walled Carbon \\ Nanotube Reinforcement on Mechanical and Conductivity \\ Properties of Sheet Molding Compound
}

\author{
Aykut Ilgaz ${ }^{*}\left(\mathbb{0}\right.$, Deniz Perin ${ }^{2}(\mathbb{0}$ \\ ${ }^{1}$ Balıkesir Üniversitesi, Fen Edebiyat Fakültesi, Fizik Bölümü, 10185, Balıkesir, Türkiye \\ ${ }^{2}$ Literatür Kimya, Balıkesir Organize Sanayi, 10100, Balıkesir, Türkiye \\ Sorumlu Yazar / Corresponding Author*: aykutilgaz@balikesir.edu.tr \\ Geliș Tarihi / Received: 17.07.2019 Araștırma Makalesi/Research Article \\ Kabul Tarihi /Accepted: 04.11.2019 DOI: 10.21205/deufmd.2020226510 \\ Atıfsekli/How to cite: ILGAZ, A., PERIN, D.(2020). Tek Duvarlı Karbon Nanotüp Takviyesinin Levha Kalıplama Bileșiğinin Mekanik ve \\ iletkenlik Özelliklerine Etkisinin İncelenmesi. DEUFMD, 22(65), 417-423. \\ Öz
}

Bu çalışmada, tek duvarlı karbon nanotüp takviyesinin doymamış polyester bazlı levha kalıplama bileşiğinin mekanik ve iletkenlik özellikleri üzerindeki etkisi araştırılmıştır. Malzemenin rijitliğinin ölçüsü olan elastisite modülü, gerilme testlerinden elde edilen gerilme dayanımı-uzama grafiklerinin elastik bölgesinden hesaplanmıștır. Karbon nanotüp katkısının standart numunenin elastisite modülünü \% 18, maksimum gerilme kuvvetini \% 47 ve tokluğunu da \% 38 oranında arttırdığı tespit edilmiştir. Doğru akım iletkenliği ise akım-voltaj ölçümleri kullanılarak hesaplanmıştır. Sonuçlar, tek duvarlı karbon nanotüp katkısının malzemenin direncini önemli ölçüde azaltıp doğru akım iletkenliğini bir milyon kat arttırdığını ortaya koymaktadır. Yalıtkan olan kompozit malzemenin, karbon nanotüp katkısıyla yalıtkanlıktan yarıiletkenlik seviyesine geldiği görülmektedir.

Anahtar Kelimeler: Tek duvarlı karbon nanotüp, Levha Kalıplama Bileşiği, Elastisite modülü, Doğru akım iletkenliği.

\begin{abstract}
In this study, the effect of single walled carbon nanotube reinforcement on mechanical and conductivity properties of unsaturated polyester-based sheet molding compound was investigated. Elasticity modulus, a measure of the stiffness of the material, was calculated from the slope in the elastic region of the tensile strength-elongation graphs obtained from tensile tests. It has been found that carbon nanotube additive increases the modulus of elasticity of standard sample by $18 \%$, maximum tensile strength by $47 \%$ and toughness by $38 \%$. The dc conductivity was also obtained for standard and carbon nanotube reinforced materials using current-voltage measurement. The results show that the addition of single-walled carbon nanotube significantly reduces the resistance of the material and increases the direct current conductivity by one million times. It is seen that the composite material, which is insulator, has increased from insulator to semiconductor level with the contribution of carbon nanotube.
\end{abstract}

Keywords: Single walled carbon nanotube, Sheet molding compound, Elasticity modulus, Direct current conductivity. 


\section{Giriş}

Kompozitler, 20.yüzyılın ikinci yarısından itibaren enerji sektöründe, doğal gaz boru hatlarında, denizcilik uygulamalarında ve sanayi alanında dayanıklılıkları, uzun ömürlü olușları ve en önemlisi düșük maliyetleri nedeniyle en çok tercih edilen malzemeler arasında kendilerine yer bulmuşlardır [1-3]. İki ya da daha fazla bileșenden olușan kompozit malzemelerin; kullanılan reçine çeşidine ve takviye malzemesine göre pek çok çeșidi mevcuttur [4].

Pres kalıplama pestili ya da piyasada bilinen adıyla SMC (sheet moulding compound); üretim hızı ve mukavemeti sayesinde otomotiv sektöründe kaput, çamurluk, far yuvaları gibi parçalarda yaygın biçimde kullanılırken korozyona ve kimyasal etkilere karșı dayanımı sayesinde de bulaşık makinesi, klima, buzdolabı gibi ev aletleri endüstrisinde öne çlkan kompozitlerden biridir [5]. Kompozitlerin bu başarısının sırrı her dönem yenilenmeye ve gelişmeye açık olmalarıdır. Özellikle son yirmi yılda kompozitlerin bu revizyon ve gelişimini sağlayan en önemli bileşenlerden birisi de karbon nanotüplerdir. İlk olarak Iijima [6] tarafından keşfedilen karbon nanotüplerin fonksiyonelleștirilmeleri ve geliștirilmeleriyle $[7,8]$ birlikte standart malzemeye katkılanması, malzemenin elastisite modülünü (Young modülü), gerilme mukavemetini ve elektrik iletkenliğini kayda değer biçimde etkilediğini göstermiștir $[9,10]$. Allaoui ve arkadaşları tarafından yapılan çalıșmada, \% 1'lik karbon nanotüp katkısının malzemeyi hem mekanik hem de elektrik iletkenliği bakımından bașka bir seviyeye taşıdığı ortaya konulmuştur [11]. Benzer bir çalıșma ve derleme Sengupta ve arkadaşları tarafından yapılmış ve karbon nanotüplerin sahip oldukları mukavemet özelliklerini entegre oldukları malzemeye başarıyla aktarabildiklerini ispatlamıştır [12].

Bu çalıșma kapsamında, standart prosedürlerle üretilen SMC malzeme ile \%1 oranında tek duvarlı karbon nanotüp (TDKN) katkılı olarak üretilen SMC malzemenin mekanik özellikleri ve doğru akım (direct current-dc) iletkenliği incelenmiștir. Malzemelerin mekanik özellikleri çekme testlerinden elde edilen grafiklerden karşılaştırmalı olarak analiz edilirken, dc iletkenlikleri ise yüksek hızlı akım-voltaj ölçümlerinden elde edilen sonuçlara bağlı olarak hesaplanmıştır. Elde edilen sonuçların ıșığında katkılı kompozit malzemelerin daha nitelikli ve daha üstün özelliklere sahip olduğu ve çeşitli alanlarda kullanılabileceği değerlendirilmektedir.

\section{Materyal ve Metot \\ 2.1. Materyal ve Üretimi}

Üretilen standart numune, \% 24 oranında doymamış polyester, \% 6 oranında dolgu maddesi, \% 1,7 oranında stiren, \% 0,4 oranında peroksit, \% 1,5 oranında çinko sülfit, \% 27,5 oranında kalsiyum karbonat, \% 0,8 oranında kıvam verici madde ve $\% 37$ oranında cam elyaf içermektedir. Eklenen karbon nanotüp miktarı ise ağırlıkça \%1 oranındadır. Numunelerin üretim akış diyagramı Şekil 1'de verilmiştir.

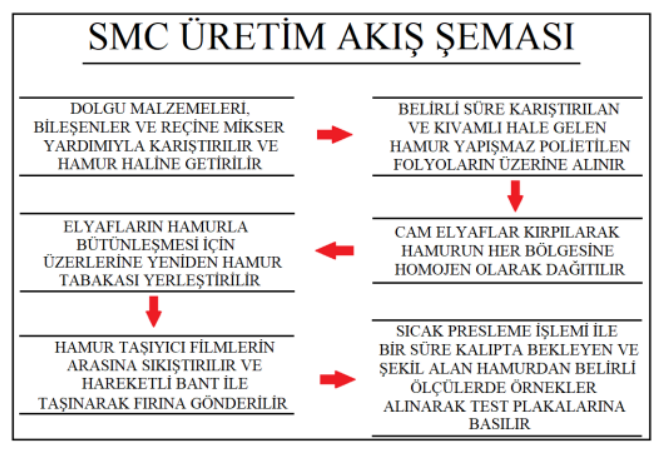

Şekil 1. Numunelerin üretim akış diyagramı

Üretim aşamasında ilk olarak dolgu malzemelerinin, bileșenlerin ve karbon nanotüpün topaklanmasını önlemek ve birbirlerine entegrasyonunu arttırarak homojen bir dağllım elde etmek için bu malzemeler ve doymamış polyester reçine mikser yardımıyla mekanik olarak sürekli karıștırılmıș ve sonunda kıvamlı hamur haline getirilmiștir. Elde edilen hamur, taşıyıcı ve yapışmaz polietilen folyoların üzerine aktarılmıştır. Bundan sonra cam elyaflar kırpılarak homojenliğin sağlanabilmesi adına hamurun her bölgesine eşit miktarda dağıtılmaya çalıșılmıștır. Kırpılan elyafların malzemeyle bütünleşmesini sağlamak amacıyla üzerlerine yeniden hamur serilmiştir. Doymamış polyesterin uçuculuğunu engellemek ve hamurlarda boșluk oluşumunun önüne geçmek için hamur taşıyıcı film arasına sıkıștırılarak optimum viskozite değerine gelinceye kadar firına gönderilmiş ve sıcak presleme işlemiyle kalıpta bekletilmiştir. 8-10 dakika kalıpta bekleyen ve șekil alan hamurdan 
$240 \mathrm{~mm} \times 140 \mathrm{~mm} \times 4 \mathrm{~mm}$ 'lik örnekler test plakalarına basılarak üretilmiştir.

\subsection{Yöntem}

\subsubsection{Mekanik Özellikler}

Dayanıklılık ve esneklik gerektiren uygulamalarda kompozit malzemelerden istenen özellik, diş bir kuvvet veya basınç altında olabildiğince yüksek gerilme kuvvetine ve esnekliğine sahip olması ve dağılıp kopmadan formunu koruyabilmesidir. Malzemenin bu özelliklerinin ne kadar üst düzeyde olup olmadığını anlamanın en etkin yolu malzemeye çekme testleri uygulamaktır. Testlerin sonucunda, malzemeye uygulanan gerilmenin boyuna uzamaya göre değișim grafiği elde edilmektedir. Gerilmenin boyuna uzamaya göre çizgisel değiştiği yani Hooke yasasına uyduğu elastik bölgede grafiğin eğimi bize elastisite modülünü vermektedir [13].

$$
\mathrm{s}=\mathrm{E} . \mathrm{e}
$$

Burada E malzemenin rijitliğinin ölçüsü olan elastisite modülü, $s$ gerilmeyi ve e biçimdeki değişim oranını temsil etmektedir. Biçim değiștirme oranı

$$
\mathrm{e}=\frac{\Delta \mathrm{L}}{\mathrm{L}_{0}}
$$

ile verilmektedir. Denklemde $\Delta \mathrm{L}$ malzemedeki uzama miktarını temsil ederken $\mathrm{L}_{o} \mathrm{da}$ malzemenin uzamadan önceki boyudur.

$\mathrm{Bu}$ çalışmada, standart ve TDKN katkılı SMC malzemeler $12 \mathrm{~mm}$ x $200 \mathrm{~mm}$ boyutlarında kesilerek Zwick Roell Z250 model çekme testi cihazına yerleștirilmiștir. Cihazın çekme hızı, her iki numune için de aynı sabit değere sahip olup $6 \mathrm{~mm} /$ dak olarak ayarlanmıştır. Kuvvet kalibrasyonu 7500-1 standardına göre yapılan cihazın sınıfi 1 olarak kaydedilmiștir [14]. Numunenin uzunluğundaki değișimin tespiti için cihaza tak kullan özelliği olan iki uzama ölçer (ekstansometre) monte edilerek kalibrasyonu ISO 7500-1 standardına uygun biçimde yapılmış olup sınıfları 1 olarak belirlenmiştir [15]. Çekme test cihazı ile eşzamanlı olarak çalıştırılan uzama ölçerlerden alınan bilgiler ölçüm sistemine bağlı datalogger kullanılarak bilgisayara aktarılmış ve TestXpert yazılım programı sayesinde çekme kuvvetine karşılık gelen uzama miktarları șeklinde veriler elde edilmiștir. Elde edilen verilerden ayrıca elastisite modülü hesaplanmıș ve TDKN katkısının malzemeyi nasıl etkilediği analiz edilmiştir.

\subsubsection{Elektriksel Özellikler}

Elektrostatik boşalma veya elektromanyetikradyo parazit koruması gibi yeterli matris iletkenliği gerektiren durumlar için karbon nanotüpler, malzeme içindeki iletken bir dolgu maddesi olarak kullanılmaktadır. İçerdiği bileșenlerin doğasına bağlı olarak yalıtkan özellik gösteren kompozitlerin elektriksel iletkenliğini açlklayan mekanizma perkolasyon ya da süzülme teorisidir [16]. Düşük katkılama yoğunluklarında karbon nanotüpler, matris içinde çeșitli bölgelere dağılırlar ancak diğer takviye bileşenlerinden boyutsal olarak daha küçük oldukları için matris içindeki görüntüleri küçük ve bağımsız kümeler halindedir. Matris içindeki karbon nanotüp miktarı artmaya başlayınca birbirlerinden ayrı olan kümeler yavaş yavaş büyümeye ve birbirlerine yakınlaşmaya hatta belirli noktalarda birbirlerine değmeye başlarlar. Süzülme eşiği adı verilen kritik konsantrasyon değerinde ise karbon nanotüpler malzeme içerisinde iletken bir ağ meydana getirirler. Bu eşik değeri, kompozit maddenin direncindeki ani bir azalmayla karakterize edilir. Kompozit malzemenin çeşidi, üretim şekli ve matrisin katkı maddesi ile etkileşimi gibi faktörler de iletkenliği etkileyen olaylardandır [17].

$\mathrm{Bu}$ çalışmada malzemelerin doğru akım iletkenliklerini hesaplamak için ise akım-voltaj ölçümleri kullanılmıştır. L=150 mm'lik uzunluğa sahip çubuk şeklindeki numunelerin akım-voltaj ölçümlerinden elde edilen eğrilerin eğimlerinin terslerinden direnç değerleri hesaplanmıştır. Direnç ile birlikte numunenin boyutları kullanılarak malzemelerin özdirenç değeri [18]

$$
\rho=R \frac{\mathrm{t}}{\frac{\mathrm{L}}{\mathrm{W}}}
$$

denklemi ile hesaplanır. Denklemde, t numunenin kalınlığ 1 ve w numunenin genişliği olup hesaplamalarda $\mathrm{t}=10 \mathrm{~mm}$ ve $\mathrm{w}=10 \mathrm{~mm}$ olarak alınmıştır. 


\section{Bulgular}

Standart SMC için gerilmeye karşıllı gelen boyuna uzama grafiği Şekil 2'de verilmiştir. Çekme testinde malzemeye uygulanan küçük zorlama ve gerilme durumlarında malzemede oluşan uzama miktarlarının küçük ve doğru orantılı artışları gözlenmiștir. Tersinir bir bölge olarak tanımlanan bu elastik bölgede malzemenin davranışı Hooke yasasına uymuş ve bu bölgeden elastisite modülü hesaplanarak Tablo 1'e kaydedilmiştir.

Tablo 1. Malzemelerin elastisite modülü, maksimum gerilme ve boyca uzama değerleri.

\begin{tabular}{lccc}
\hline \multicolumn{1}{c}{ Malzeme } & $\begin{array}{c}\text { Elastisite } \\
\text { Modülü }\end{array}$ & $\begin{array}{c}\text { Maksimum } \\
\text { Gerilme }\end{array}$ & $\begin{array}{c}\text { Boyca } \\
\text { Uzama }\end{array}$ \\
\hline $\begin{array}{l}\text { Standart } \\
\text { SMC }\end{array}$ & $18,2 \mathrm{GPa}$ & $77 \mathrm{MPa}$ & $1,16 \mathrm{~mm}$ \\
$\begin{array}{l}\text { TDKN katkılı } \\
\text { SMC }\end{array}$ & $21,3 \mathrm{GPa}$ & $113 \mathrm{MPa}$ & $1,44 \mathrm{~mm}$ \\
& & &
\end{tabular}

Test cihazındaki malzemeyi tutan çeneler birbirlerinden uzaklaștıkça SMC içinde kalıcı deformasyonlar meydana gelmeye başlamıştır. Kısmen de olsa esnekliğin var olduğu bu durumda malzeme içinde tersinmez yani geri döndürülemez bir süreç başlamıștır. SMC malzemenin kimyasal yapısının bozulmaya başladığı bu durum yaklaşık 77 MPa'lık gerilme değerine kadar devam eder. Giderek deforme olan malzeme bu gerilme değerinde 1,16 mm'lik uzama gösterdikten sonra kopma göstermiştir.

Şekil 3'de görüldüğü gibi TDKN ile güçlendirilen SMC malzemede de fonksiyonun davranışı benzer olmakla beraber gerilme ve uzama miktarı artmıştır. Elastik bölgeden elastisite modülü hesaplanmış ve Tablo 1'e kaydedilmiștir. Değerlerden görüldüğü gibi kendini oluşturan karbon atomlarının dizilişleri nedeniyle kırılmaya karşı dayanıklı ve yüksek elastisite modülüne sahip olan tek duvarlı karbon nanotüplerin standart malzemeye eklenmesi malzemenin de elastisite modülünü arttırıcı etki yapmıştır.

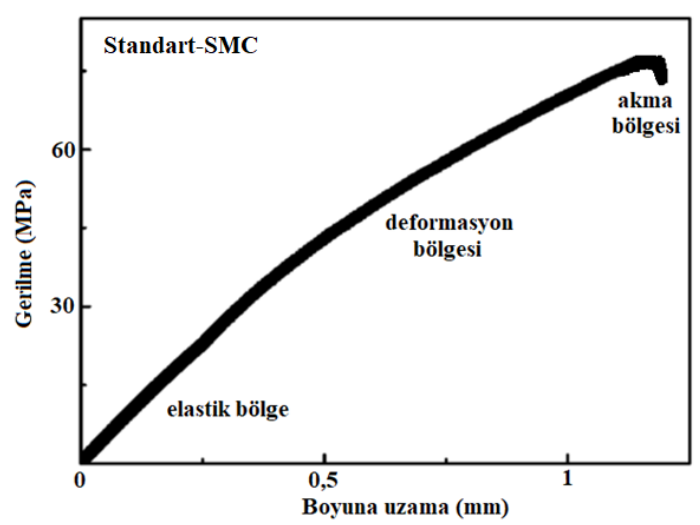

Şekil 2. Standart SMC'ye uygulanan gerilimin malzemede oluşan boyuna uzama miktarına göre değişimi.

Bununla birlikte grafiklerin karşılaştırılmalarından görüleceği üzere TDKN katkısı malzemenin gerilme ve uzama değerini arttırmıștır. Standart numune için $77 \mathrm{MPa}$ olan maksimum gerilme değeri $113 \mathrm{MPa}$ 'a, maksimum uzama miktarı da 1,16 mm'den 1,44 mm'ye artıș göstermiştir. Çekme ölçümleri göstermiştir ki malzemeye TDKN eklenmesi bileşenler arasındaki bağların şiddetini arttırarak malzemeyi mukavemet gerektiren uygulamalarda bir adım öne çıkarmaktadır. Malzemenin kopana değin soğurduğu toplam enerjiyi ifade eden tokluk değeri gerilme-uzama grafiklerinin altında kalan alandan bulunur. Kompozitin ana bileșeni olan matrisin ve polyester gibi kullanılan reçinenin hasar uzaması geciktikçe tokluk değeri artmaktadır. Eğer malzemenin hasar uzaması düşükse malzeme kırılgan hale gelir. Grafikler incelendiğinde TDKN katkısının malzemenin gerilmeye dayanımını arttırarak tokluğunu da \% 38 oranında arttırdığı tespit edilmiştir. 
DEÜ FMD 22(65), 417-423, 2020

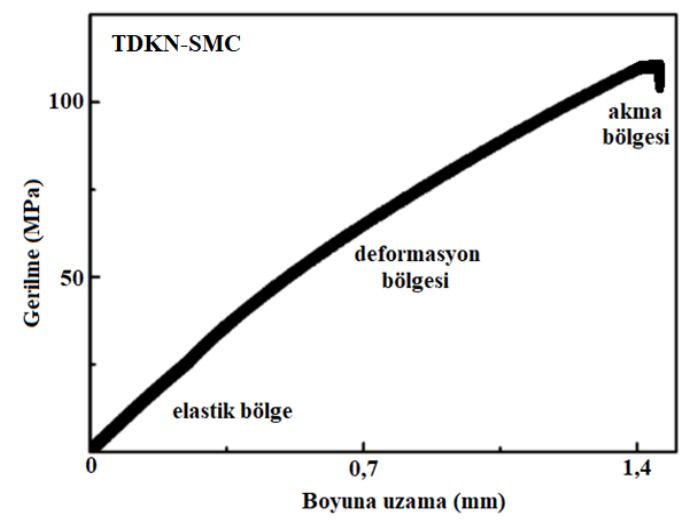

Şekil 3. TDKN-SMC'ye uygulanan gerilimin malzemede oluşan boyuna uzama miktarına göre değișimi.

Standart SMC'nin doğru akım iletkenliğinin voltaja bağlı olarak değişimi Şekil 4'de verilmiştir. Yaklaşık olarak $10 \mathrm{~V}$ değerine kadar grafiğin fonksiyonu çizgisel davranış göstererek Ohm yasasına uymaktadır. Voltaj değeri küçük aralıklarla arttırıldığında ise akımın artış hızı yavaşlar ve fonksiyon çizgisellikten sapar. 25 V'luk maksimum voltaj değerinde ise numune içinden geçen akım ancak nanoamper seviyelerine ulaşır.

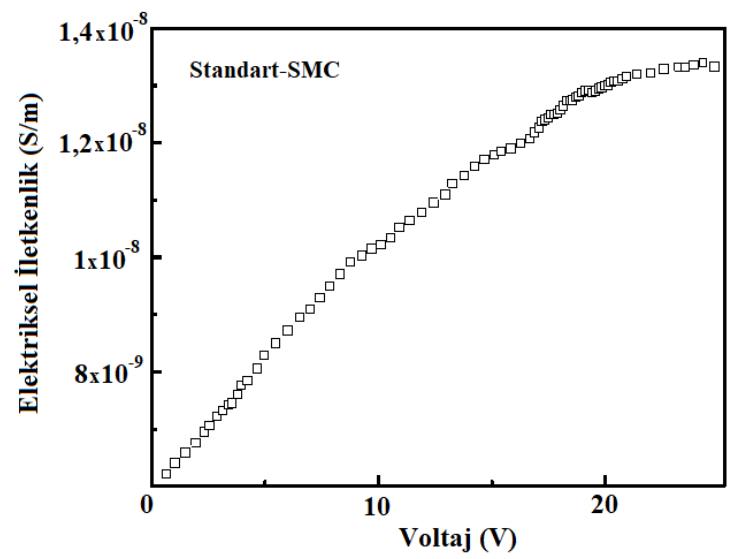

Şekil 4. Standart SMC'nin doğru akım iletkenliğinin voltaja bağlı olarak değişimi.

TDKN ile güçlendirilmiș SMC malzemenin akım-voltaj karakteristiğinden çıarılan iletkenlik-voltaj grafiği ise Şekil 5'te görülmektedir. Grafiklerin davranışları benzer olmakla beraber iletkenlik değerleri arasındaki fark dikkat çekicidir. Sahip oldukları uzunluk, vektör ve yarıçaplara bağlı olarak yariletken veya iletken özelliklere sahip olabilen TDKN'lar \% 1 oranında bir katkıyla dahi yalıtkan bir malzemeyi kendi iletkenlik seviyelerine yaklaştırabilmişlerdir. Sonuç olarak kullanım amacına uygun olarak TDKN'lerin kompozit malzemelerin elektriksel özelliklerini kontrol etmede ideal malzemelerden biri olduğu ortaya konulmuştur. 
DEÜ FMD 22(65), 417-423, 2020

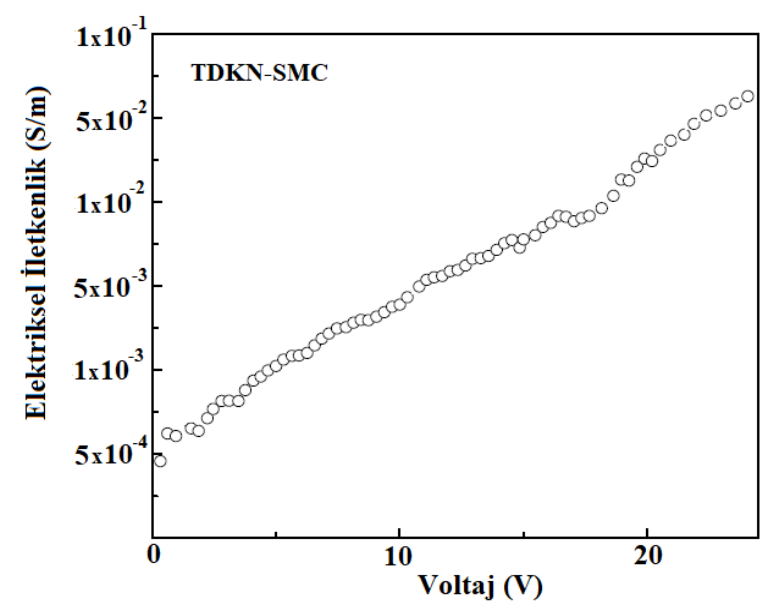

Şekil 5. TDKN-SMC'nin doğru akım iletkenliğinin voltaja bağlı olarak değişimi.

\section{Tartışma ve Sonuç}

$\mathrm{Bu}$ çalışmada, standart bileşenler ve prosedürler ile üretilen SMC malzemeye TDKN takviyesi yapılarak mekanik ve iletkenlik özelliğinin değişimi özel ölçüm teknikleri kullanılarak karşılaştırmalı olarak analiz edilmiștir. Çekme testi deneylerinde, standart ve TDKN katkılı numunelerden eşit boylarda kesilerek ayrı ayrı 2 adet hazırlanmıș olup her malzeme için ölçüm numune kopana kadar devam ettirilmiştir. Elde edilen değerlerin ortalaması, standart ve TDKN katkılı SMC için deney sonucu olarak kullanılmıştır. Düşük gerilme değerlerinde her iki malzemede oluşan uzama değerleri lineer bir davranış gösterirken gerilmenin artmasıyla standart malzeme daha erken deformasyon ve akma bölgesine girerek sonucunda da kopmuştur. Karbon nanotüp takviyesinin ise malzemenin dayanabildiğ gerilme değerini ve malzemenin sahip olduğu elastisite modülünü önemli ölçüde arttırdığ görülmüștür. Nanotüp konsantrasyonu arttırıldığında ve malzemenin homojenliği arttırıldığında bu etkinin daha belirgin olacağı düşünülmektedir. Gerilme-boyuna uzama grafiğinin altında kalan malzemenin tokluğunu verdiğinden tek duvarlı karbon nanotüp katkısının reçine ve diğer bileşenlerle kimyasal uyumu arttırarak malzemenin tokluğunu da arttırdığı söylenebilir.

Standart üretilen SMC, içerdiği bileşenlerin doğasına uygun olarak $\mathrm{G} \Omega$ mertebelerinde dirence sahip olup yalıtkan bir yapıdadır. \% 1 oranında eklenen tek duvarlı karbon nanotübün kritik konsantrasyonu aştığı, kompozit içinde birbiriyle temas eden iletken bir ağ oluşturup direnç seviyesini $\mathrm{k} \Omega$ seviyelerine çektiği ve bunun sonucu olarak da doğru akım iletkenliğini bir milyon kat arttırdığı ortaya konulmuştur. Nanotüp konsantrasyonunun arttırılması dayanıklılığı etkilediği kadar elektriksel iletkenliği de birinci derecede etkileyen parametrelerdendir. Nanotüp yoğunluğu arttırılırsa malzemenin iletkenliğinin yariletken seviyesinden iletken seviyesine çekilebileceği düşünülmektedir.

Sonuç olarak sahip olduğu eşsiz özellikler nedeniyle tek duvarlı karbon nanotübün malzemenin hem mekanik hem de elektriksel özelliklerini olumlu olarak etkilediği ispatlanmıștır. Dolayısıyla hem mukavemet gerektiren uygulamalarda hem de elektriksel iletkenliğin gerekli olduğu durumlarda TDKN katkılı SMC malzemelerin kendilerine önemli bir uygulama alanı yaratacakları açıkça görülmektedir. 
DEÜ FMD 22(65), 417-423, 2020

\section{Teşekkür}

Yazarlar, çalışma sırasında kullanılan takviye malzemelerinin temininde ve numunelerin üretilmesindeki katkılarından dolayı Literatür Kimya'ya teşekkürlerini sunar.

\section{Kaynakça}

[1] Zingaro, J.R. 1996. Phenolic Composites in the Aircraft Industry and the Necessary Transition to the Mass Transit Rail Industry, paper presented at the 51st Annual Conf., Composites Institute, Society of the Plastics Industry Inc.

[2] Cizmeci, Ö.S. 2006. Roket ve Füzelerde Kompozit Malzeme Kullanımının İncelenmesi, Yıldız Teknik Üniversitesi, Makine Malzemesi ve İmalat Teknolojisi Anabilim Dalı, Lisans Bitirme Tezi, İstanbul.

[3] Acar, V., Akbulut, H., Sarıkanat, M., Seydibeyoğlu, M.Ö., Seki Y., Erden S. 2013. Karbon Elyaf Takviyeli Prepreg Kompozitlerde Arayüzey Mekaniğinin Karbon Nanoyapı Katkısıyla İyileștirilmesi. Makine Teknolojileri Elektronik Dergisi, Cilt.10, s.43-51.

[4] Thomason J.L. 1995. The interface region in glass fibre-reinforced epoxy resin composites: 2, Water absorption,voids and the interface. Composites, Cilt.26, s.477-485. DOI: 10.1016/00104361(95)96805-G.

[5] Borrachero, B. O., Caballero, S. S., Fenollar, O Selles, M. A. 2019. Natural-Fiber-Reinforced Polymer Composites for Automotive Parts Manufacturing, Key Engineering Materials, Cilt.793, s.9-16. DOI: 10.4028/www.scientific.net/KEM.793.9.

[6] Lijima, S. 1991. Helical Microtubules of Graphitic Carbon, Nature, Cilt.354, s.56-58. DOI: 10.1038/354056a0.

[7] Bethune, D. S. and Klang, C. H. and de Vries, M. S. and Gorman, G. and Savoy, R. and Vazquez, J. and Beyers, R. 1993. Cobalt-catalysed growth of carbon nanotubes with single-atomic-layer walls. Nature, Cilt.363, s.605-607. DOI: 10.1038/363605a0.

[8] Chen, G.X., Kim, H.S., Park, B.H., Yoon, J.S. 2005 Controlled Functionalization of Multiwalled Carbon Nanotubes with Various Molecular-Weight Poly(Llactic acid), J. Phys. Chem., Cilt.109, s. $22237-$ 22243. DOI: $10.1021 /$ jp054768n.

[9] Xiong, J., Zheng, Z., Qin, X., Li, M., Li, H., Wang, X. 2006. The thermal and mechanical properties of a polyurethane/multi-walled carbon nanotube composite, Carbon, Cilt.44, s.2701-2707. DOI: 10.1016/j.carbon.2006.04.005.

[10] Chen, W., Tao, X., Liu, Y. 2006. Carbon nanotubereinforced polyurethane composite fibers, Composites Science and Tech., Cilt.66, s.30293034. DOI:10.1016/j.compscitech.2006.01.024.

[11] Allaoui, A., Bai, S., Cheng, H. M., Bai, J. B. 2002. Mechanical and electrical properties of a MWNT/epoxy composite, Composites Science and Technology, Cilt.62, s.1993-1998. DOI: 10.1016/S0266-3538(02)00129-X

[12] Sengupta, R., Bhattacharya, M., Bandyopadhyay, S Bhowmick, A. K. 2011. A review on the mechanical and electrical properties of graphite and modified graphite reinforced polymer composites, Progress in Polymer Science, Cilt.36, s.638-670. DOI: 10.1016/j.progpolymsci.2010.11.003.

[13] Hosford, W.F. 1992. Overview of Tensile Testing, Tensile Testing. $2^{\text {nd }}$ edition. ASM International, s. $1-24$.

[14] ISO 7500-1, 2004. Metallic materials -- Verification of static uniaxial testing machines -- Part 1: Tension/compression testing machines Verification and calibration of the force-measuring system.

[15] TS EN ISO 9513, 2005. Metal malzemeler-Tek eksenli deneylerde kullanılan ekstansometrelerin kalibrasyonu.

[16] Coleman, J. N., Curran, S., Dalton, A. B., Davey, A. P., McCarthy, B., Blau, W. 1998. Percolationdominated conductivity in a conjugated-polymercarbon nanotube composite, Phys. Rev. B Condens. Matter Phys., Cilt.58, s. 7492-7495. DOI: 10.1103/PhysRevB.58.R7492.

[17] Yuan, X. 2007. Experimental study of Electrical conductivity of carbon nanotube, nanofiber buckypapers and their composites. A Thesis submitted to the Department of Industrial \& Manufacturing Engineering, Maste of Science thesis, 118S, Florida.

[18] Pathania, D. and Singh, D. 2009. A review on electrical properties of fiber reinforced polymer composites, International Journal of Theoretical \& Applied Sciences, ISSN : 0975-1718, Cilt.1, s.34-37. 